Jurnal Onoma: Pendidikan, Bahasa dan Sastra

\title{
Pengembangan Buku Ajar Mata Kuliah Bahasa Indonesia untuk Implementasi Merdeka Belajar Kampus Merdeka
}

\author{
Anastasia Baan, Resnita Dewi \\ Universitas Kristen Indonesia Toraja \\ anasbaan@ukitoraja.ac.id, resnita@ukitoraja.ac.id
}

\begin{abstract}
Abstrak
Penelitian ini bertujuan untuk mengembangkan buku ajar Bahasa Indonesia. Penelitian ini merupakan penelitian pengembangan dengan model ADDIE (Analysis, Design, Development, Implementation, Evaluation). (1) Tahap analysis meliputi (a) analisis kurikulum; (b) analisis kebutuhan mahasiswa 2) Tahap design meliputi (a) materi pokok; (b) desain buku ajar. (3) Tahap development dilakukan dengan menyusun dan mengetik keseluruhan materi yang telah didesain berdasarkan analisis kebutuhan. (4) Tahap implementation merupakan tahap uji kelayakan penggunaan buku ajar yang telah disusun. (5) Tahap evalution dilakukan untuk mengevaluasi buku ajar yang dikembangkan untuk implementasi Kurikulum Merdeka Belajar-Kampus Merdeka yang meliputi hasil validasi buku ajar oleh dosen ahli materi dan ahli media, hasil penilaian buku ajar oleh dosen, hasil angket respon buku ajar oleh mahasiswa, hasil postes mahasiswa.
\end{abstract}

Kata Kunci: Pengembangan, Buku Ajar, Bahasa Indonesia

\section{Pendahuluan}

Salah satu isu strategis bidang akademik untuk perguruan tinggi saat ini adalah implementasi Merdeka Belajar-Kampus Merdeka. Kebijakan ini memberikan kesempatan kepada mahasiswa untuk mengikuti pembelajaran di laur program studinya. Pembelajaran dengan cara ini memberi kebebasan kepada mahasiswa untuk melakukan kegiatan yang berhubungan dengan perkuliahannya. Kegiatan perkuliahan tersebut meliputi proyek desa, magang, praktik industri, dan kegiatan lainnya yang dapat membuat mahasiswa mempersiapkan masa depannya sejak dini dengan sebaik mungkin. Berdasarkan hal tersebut, universitas dituntut untuk merevisi kurikulum sebagai salah satu cara memfasilitasi implementasi Merdeka Belajar-Kampus Merdeka.

Kurikulum di perguruan tinggi, termasuk Universitas Kristen Indonesia Toraja, menempatkan Bahasa Indonesia sebagai mata kuliah umum yang diwajibkan. Hal ini bertujuan agar lulusan perguruan tinggi selain memiliki kompetensi lulusan di bidangnya, juga mampu berkomunikasi dengan baik dan benar, baik secara lisan maupun tertulis. Kemampuan berkomunikasi melalui bahasa merupakan modal bagi para alumni UKI Toraja untuk beradaptasi dalam dunia kerja.

Tujuan pembelajaran Bahasa Indonesia di Universitas Kristen Indonesia Toraja tidak hanya agar mahasiswa lulus mata kuliah tersebut, melainkan mampu berkomunikasi dengan menggunakan Bahasa Indonesia sesuai dengan kaidah kebahasaan yang baik dan benar. Terimplementasinya kemampuan berbahasa mahasiswa UKI Toraja akan berdampak positif pada kemampuan mereka dalam berkomunikasi baik secara lisan maupun tertulis, untuk semua aktivitas baik akademik maupun nonakademik.

Sarana penunjang dalam perkuliahan Mata Kuliah Bahasa Indonesia mutlak diperlukan untuk membantu dalam capaian hasil pembelajaran yang efektif sesuai 
Jurnal Onoma: Pendidikan, Bahasa dan Sastra

tuntutan Merdeka Belajar Kampus Merdeka. Sarana tersebut antara lain buku ajar Mata Kuliah Umum Bahasa Indonesia (Taufiq, 2015: Retno dan Zaim, 2012; Nurwanti dan Sitti; 2015). Berdasarkan hasil observasi awal yang dilakukan, ditemukan fakta bahwa belum ada buku ajar Mata Kuliah Umum Bahasa Indonesia yang khusus dimiliki oleh UKI Toraja dan menjadi patokan oleh semua dosen dalam mengajar. Selama ini, setiap dosen Bahasa Indonesia mengajar dengan menggunakan materi masing-masing, sehingga materi yang diajarkan menjadi tidak seragam, meskipun diajarkan pada program studi yang sama.

Berdasarkan hasil observasi tersebut, maka perlu dikembangkan buku ajar Mata Kuliah Umum Bahasa Indonesia untuk Mahasiswa UKI Toraja. Pengembangan buku tersebut penting untuk mendukung implementasi Merdeka Belajar Kampus Merdeka mata kuliah Bahasa Indonesia.Selain itu diharapkan, dengan adanya buku tersebut materi-matari dasar dari Bahasa Indonesia dapat dibawakan secara seragam oleh semua dosen Bahasa Indonesia. Selain itu, pengembangan buku ajar tersebut perlu dilakukan mengingat banyaknya fakultas di UKI Toraja yang semuanya memprogramkan mata kuliah Bahasa Indonesia, mulai dari Fakultas Keguruanan dan Ilmu Pendidikan, Fakultas Teologi, Fakultas Teknik, Fakultas Ekonomi, dan Fakultas Pertanian. Karena banyaknya Fakultas di UKI Toraja, maka buku ajar tersebut akan dirancang semaksimal mungkin agar dapat bersifat universal untuk semua fakultas.

\section{Kajian teori}

\section{Kurikulum Merdeka Belajar Kampus Merdeka}

Kurikulum merupakan seperangkat rencana dan pengaturan mengenai tujuan, isi, dan bahan pelajaran serta cara yang digunakan sebagai pedoman penyelenggaraan kegiatan pembelajaran untuk mencapai tujuan Pendidikan Tinggi. Kurikulum Merdeka Belajar Kampus Merdeka adalahupaya memberi kebebasan dan otonomi kepada lembaga pendidikan, dan merdeka dari birokratisasi, dosen dibebaskan dari birokrasi yang berbelit serta mahasiswa diberikan kebebasan untuk memilih bidang yang mereka sukai.

\section{Pengembangan Buku Ajar}

Pembelajaran Bahasa Indonesia merupakan pembelajaran keterampilan berbahasa baik secara teoritis, maupun secara praktif. Oleh karena itu, diperlukan pengembangan sarana pembelajaran yang berupa buku ajar. Sarana penunjang dalam perkuliahan Mata Kuliah Bahasa Indonesia mutlak diperlukan untuk membantu dalam capaian hasil pembelajaran yang efektif sesuai tuntutan Merdeka Belajar Kampus Merdeka. Sarana tersebut antara lain buku ajar Mata Kuliah Umum Bahasa Indonesia (Taufiq, 2015: Retno dan Zaim, 2012; Nurwanti dan Sitti;2015) .

\section{Metode Penelitian}

Penelitian ini merupakan jenis penelitian pengembangan (Sugiyono, 2010; Alamsyah, 2012: Alfianika, 2014), yaitu penelitian yang mengembangkan dan menghasilkan sebuah produk. Produk yang dihasilkan dalam penelitian ini adalah buku ajar mata kuliah umum Bahasa Indonesia. Penelitian ini akan dilaksanakan di UKI Toraja pada tahun 2019-2020. Penelitian pengembangan ini menggunakan model ADDIE, yaitu Analysis, Design, Development, Implementation, Evaluation (Benny, 2009:126). Data dalam penelitian ini dikumpulkan dengan teknik observasi, interview, angket dan tes. 
Jurnal Onoma: Pendidikan, Bahasa dan Sastra

\section{Pembahasan}

Pengembangan buku ajar ini dilakukan dengan tahap-tahap model ADDIE, yaitu Analysis, Design, Development, Implementation, Evaluation.

1.Tahap Analisis (Analysis)

Untuk pengembangan buku ajar perlu dilakukuan analisis berupa:

a. Analisis kurikulum

Analisis kurikulum perlu dilakukan untuk mengetahui kebutuhan pengembangan yang diembankan oleh kurikulum, agar dapat diwujudnyatakan melalui proses pembelajaran. Peralihan kurikulum dapat berdampak pada peralihan substansial yang ingin dicapai, sehingga perlu dilakukan analisis kurikulum, untuk memetakan kembali capaian yang dituntut melalui kurikulum.

b. Analisis kebutuhan mahasiswa.

Analisis kebutuhan mahasiswa dilakukan untuk memperoleh data dan penjelas mengenai kebutuhan mahasiswa atas pembelajaran mata kuliah Bahasa Indonesia. Berdasarkan observasi yang dilakukan, didapatkan informasi:

1) Mahasiswa membutuhkan sumber belajar yang dapat memudahkan mahasiswa pembelajaran. Selama ini pembelajaran mata kuliah Bahasa Indonesia berlangsung hanya dengan menggunakan materi power point dari dosen.

2) Mahasiswa masih kurang fokus dalam pembelajaran mata kuliah Bahasa Indonesia karena ketidaadaan buku acuan yang dijadikan pedoman dalam memudahkan pembelajaran.

3) Masih banyak mahasiswa yang belum fokus dalam pembelajaran karena materi yang disampaikan oleh dosen dianggap kurang menarik dan cenderung membosankan oleh mahasiswa.

4) Dalam pembelajaran mata kuliah Bahasa Indonesia dosen masih menjadi sumber belajar utama.

5) Dosen belum menyusun buku acuan atau buku ajar yang dapat menjadi dasar dalam pembelajaran mata kuliah Bahasa Indonesia

\section{Tahap Desain (Design)}

Tahap desain meliputi:

a. Desain materi pokok yang akan dikembangkan.

Materi pokok yang akan dikembangkan ditentukan berdasarkan hasil analisis kurikulum dan analisis kebutuhan mahasiswa yang disesuaikan dengan implementasi Kurikulum Merdeka Belajar-Kampus Merdeka. Selanjutnya dideskripsikan pokokpokok dari materi tersebut agar sesuai dengan tingkat keluasan dan kedalaman kompetensi yang akan diajarkan pada mahasiswa.

b. Desain buku ajar.

Desain unsur-unsur buku ajar, terdiri atas:

1) Pendahuluan

a) Sampul

b) Kata pengantar

c) Prakata

Halaman | 329 
Jurnal Onoma: Pendidikan, Bahasa dan Sastra

d) Daftar isi

2) Isi

a) Materi

3) Penutup

a) Daftar Pustaka

\section{Tahap Pengembangan (Development)}

Pengembangan dilakukan dengan menyusun dan mengetik keseluruhan materi yang telah didesain berdasarkan analisis kebutuhan. Untuk memastikan bahwa materi yang disusun sudah sesuai dengan analisis kebutuhan, maka selama penyusunan dilakukan revisi, berdasarkan koreksi dari ahli atau pakar. Setelah buku ajar layak untuk divalidasi, selanjutnya buku ajar divalidasi oleh ahli materi dan ahli media untuk mendapatkan kelayakan untuk selanjutnya diterapkan atau diuji coba di kampus.

4. Tahap Implementasi (Implementation)

Implementasi merupakan tahap uji kelayakan penggunaan buku ajar yang telah disusun. Dalam tahap ini terdapat pemberian respon dari mahasiswa untuk mengetahui telah terjawab tidaknya kebutuhan mahasiswa dalam pembelajaran mata kuliah bahasa Indonesia.

5. Tahap Evaluasi (Evaluation)

Evaluasi dilakukan untuk mengevaluasi buku ajar yang dikembangkan untuk implementasi Kurikulum Merdeka Belajar-Kampus Merdeka yang meliputi:

a. hasil validasi buku ajar oleh dosen ahli materi dan ahli media.

b. hasil penilaian buku ajar oleh dosen.

c. hasil angket respon buku ajar oleh mahasiswa.

d. hasil postes mahasiswa.

\section{Simpulan}

Tujuan pembelajaran Bahasa Indonesia di Universitas Kristen Indonesia Toraja tidak hanya agar mahasiswa lulus mata kuliah tersebut, melainkan mampu berkomunikasi dengan menggunakan Bahasa Indonesia sesuai dengan kaidah kebahasaan yang baik dan benar. Terimplementasinya kemampuan berbahasa mahasiswa UKI Toraja akan berdampak positif pada kemampuan mereka dalam berkomunikasi baik secara lisan maupun tertulis, untuk semua aktivitas baik akademik maupun nonakademik. Untuk itu, sebagai salah satu upaya peningkatan kualitas pembelajaran, diperlukan buku ajar Bahasa Indonesia yang mudah dimengerti dan dipahami oleh mahasiswa. 
Jurnal Onoma: Pendidikan, Bahasa dan Sastra

\section{Daftar Pustaka}

Alamsyah, N.,Kartono, dan Rochmad. (2012).Pengembangan Perangkat Pembelajaran Matematika Model Cooperative Learning Metode Two Stay Two Stray Berbasis Konstruktivisme Pada Materi Trigonometri Kelas X. Unnes Journal of Research Mathematics Education,1(1): 29-35.

Alfianika,N., Atmazaki., dan Abdurahman. (2014).Pengembangan Model Modul Pembelajaran Bahasa Indonesia Berbasis Investigasi Kelompok (Group Investigation)pada Materi Menulis Karangan Ilmiah Siswa Kelas XI SMA N 8 Padang.Jurnal Bahasa, Sastra dan Pembelajaran. 2(2): 47-58

Anastasia Baan, Resnita Dewi, Roni La'bira, \& Theresyam Kabanga'. (2019). REVOLUSI MENTAL MELALUI NILAI KEARIFAN LOKAL PADA SISWA SEKOLAH DASAR DI KABUPATEN TANA TORAJA.Seminar Internasional Riksa Bahasa. Retrieved from http://proceedings.upi.edu/index.php/riksabahasa/article/view/1056

Benny A. Pribadi. (2019). Model Desain Sistem Pembelajaran. Jakarta: PT Dian Rakyat. Daniel Muijs dan David Reynolds. (2018). Effecctive Teaching: Teoori dan Aplikasi edisi ke2, terj. Helly Prajitno Soetjipto dan Sri Mulyantini Soetjipto.Yogyakarta: Pustaka Pelajar.

Dedi Supriadi. (2010). Anatomi Buku Sekolah di Indonesia: Problematika Penilaian, Pentebaran dan Penggunaan Buku Pelajaran, Buku Bacaan dan Buku Sumber.Yogyakarta: Adicipta.

Depdiknas.(2018). Panduan PengembanganBahan Ajar. Jakarta: Direktorat Pembinaan Sekolah Menengah Atas, Dirjen Manajemen Pendidikan Dasar dan Menengah, Depdinas.

Nurwanti, danSiti Samhati Karomani, S.S. (2015).Pengembangan Modul Bahasa Indonesia Berbasis Life Skillsuntuk Kelas X SMK Di Kota Metro. Jurnal Bahasa, Sastra, dan Pembelajarannya. 2(4): 42-53

Prastowo, A. 2011.Panduan Kreatif Membuat Bahan Ajar Inovatif. Jogjakarta: Diva Press

Retno Purnama Irawati, R. dan Zaim Elmubarok, Z. (2012). Pengembangan Buku Ajar Bahasa Indonesia Tematik Berkarakter Bagi Siswa SD Melalui Sastra Anak. Artikel Ilmiah. Semarang: FBS Universitas Negeri Semarang

Sugiyono. (2010). Metode Penelitian Pendidikan Pendekatan Kuantitatif, Kualitatif, dan R\&D. Bandung: Alfabeta

Taufiq, F.( 2015). Pengembangan Modul Pembelajaran Bahasa Indonesia Dengan Aplikasi Mobile Learning Untuk Meningkatkan Kemandirian Belajar Siswa Kelas VIII MTs Madrasatul Qur'an Tebuireng Jombang Tapel 2013/2014. Jurnal NOSI. 2(8): 52-60 